\title{
Roentgenographic Study of Cavus Foot Deformity in Friedreich Ataxia Patients: Preliminary Report
}

\author{
P. ALLARD, J.P. SIROIS, P.S. THIRY, G. GEOFFROY, M. DUHAIME
}

SUMMARY: The preliminary results based on a three year retrospective study in cavus foot deformity of forty-four Friedreich ataxia patients regularly seen at the Neuromuscular Disease Clinic of SainteJustine Hospital have been presented. An accurate "weight-bearing" foot stereoradiographic technique has been recently developed by our group. Since the follow-up period with this device is not sufficient to provide statistical information, the conventional non-weight bearing technique has been utilized in this study to enable a possible comparison between the radiographs of ambulant and non-ambulant patients. Due

RÉSUME: Les résultats d'une étude rétrospective de trois années sur l'évolution $d u$ pied creux chez quarante-quatre patients atteints d'ataxie de Friedreich sont présentés. Ces patients ont été régulièrement suivis à la clinique des maladies neuro-musculaires de l'hopital SainteJustine. Un appareil permettant la prise de radiographies normalisées des pieds avec charge a été développé dans nos laboratoires. Cependant, l'utilisation en clinique de cet appareil est tróp récente pour produire des résultats statistiquement valables. La technique conventionnelle de prise de radiographies du pied sans charge a été utilisée dans cette étude pour permettre une comparaison possible entre les to the present technique, the results of this study must be interpreted with caution.

For 132 pairs of radiographs, 28 parameters have been analyzed. Four of these, namely the calcaneal inclination angle, the first metatarsal inclination angle, the inferior cortex of calcaneus-first metatarsal angle and the first-fifth metatarsals angle, were of particular interest. From these parameters, a preliminary quantitative description of cavus foot deformity in Friedreich's ataxia has been attempted. Three stages of evolution have been tentatively identified for this type of neurological disorder.

radiographies des patients ambulants et non-ambulants. Les résultats obtenus d̀ l'aide de cette technique doivent cependant être interprétés avec circonspection.

De 132 paires de radiographies, 28 paramètres ont été analysés. Quatre d'entre-eux, à savoir; l'angle d'inclinaison $d u$ calcanéum, l'angle d'inclinaison $d u$ premier métatarsien, l'angle calcanéumpremier métatarsien et l'angle du premiercinquième métatarsien sont plus particulièrement d'intérêt. Les résultats obtenus de l'étude de ces paramètres représentent une première tentative d'une description quantitative du pied creux dans l'ataxie de Friedreich. Trois stades d'évolution ont été principalement identifiés.
From the Pediatric Research Center, Sainte-Justine Hospital and the Department of Mechanical Engineering, Ecole Polytechnique de Montréal.

Reprint Requests for the complete supplement (Phase Three, Part Two) to: Prof. André Barbeau, Clinical Research Institute of Montreal, 110 Pine Avenue West, Montréal, Quebec, Canada, H2W 1R7.

\section{INTRODUCTION}

The dual function of the foot, namely that of support and propulsion, is mainly achieved by its longitudinal arches (Napier, 1957). The lateral arch consisting of the calcaneus, cuboid and the fourth and fifth metatarsals, provides the structural base to maintain the foot's static equilibrium. The medial arch, consisting of the calcaneus, talus, the cuneiforms and the other three metatarsals, constitutes the dynamic portion of the foot which is responsible for bringing about forward body movement. An exaggeration of this medial arch, making it more acute to that of its normal configuration, results in a pes cavus deformity which is almost invariably associated with some clawing of the toes (Tyrer, 1975). Such a deformity essentially located in this strategic portion of the foot can alter gait patterns resulting in additional callosities, foot ailments as well as a precarious gait. The etiology of pes cavus is still obscure. Brewerton et al. (1963), in a review article, list twenty-two theories postulated between 1867 and 1952 on the mechanisms involved in leading to cavus foot deformities. Its pathomechanics and those of similar foot deformities such as in pes cavovarus and pes equinocavovarus, are not completely understood (Paulos et al., 1980). Nevertheless, a general description of their evolution is available from the literature.

Meary (1967) points out that in pes cavus, the first metatarsal is retracted into a plantar flexed position whereas the fifth metatarsal remains horizontal. When the first metatarsal becomes irreductable due to an opposing force of the tensed plantar fascia, the forefoot becomes pronated by $20^{\circ}$ to $30^{\circ}$ with respect to the hindfoot. While weight- 
bearing, the patient cannot tolerate the excessive pressure developed on the head of the first metatarsal. He has to compensate for the forefoot pronation by a supination of the calcaneus. These movements do not occur in the same plane but most probably about certain fixed axes of rotation located in several planes (Hicks, 1952; Inman, 1976).

Though a classification based on clinical observations is found in the literature (Turek, 1977), a quantitative description detailing how the bony structures interact is still, according to the authors, to be understood. This lack of information combined with inconsistent results in the applied treatment lead to many empirical and nonstandardized modes of treatment (Paulos et al., 1980).

In neuromuscular disorders where cavus deformities are seen, most authors agree that no consistent pattern of muscle imbalance exists and that each patient must be carefully evaluated (Bentzen, 1933; Garceau and Brahms, 1956). Several studies (Brewerton et al., 1963; Paulos et al., 1980) pertaining to the evolution of pes cavus are based on a random type of population including some of the following: muscular atrophy, myelodysplasia, poliomyelitis, polyneuritis trauma and cerebral palsied patients.

Less is known about foot deformities in Friedreich ataxia patients. This scarce neurological disorder makes it difficult to carry out an adequate and analytical study. Thus little is known about the disease itself as well as its management. Recent studies by Barbeau et al. $(1976,1978,1979)$ have shed new light mostly on the biochemical aspect of the etiology of this entity. Concurrently with Barbeau's studies, a research program on the pathomechanics of cavus foot deformities in Friedreich's ataxia patients was initiated at Sainte-Justine Hospital. In an initial attempt to quantitatively describe the pathomechanics of cavus feet, it was thought necessary to investigate its progression from the onset to the time where severe structural deformation had set into the foot.

This paper presents preliminary results of a three year retrospective study on the evolution of cavus foot deformity in twenty-four boys and twenty girls diagnosed as having Friedreich's ataxia. These patients were regularly seen in the Neuromuscular Disease Clinic at Sainte-Justine Hospital.

\section{METHOD}

Roentgenographical techniques are often used to assess foot deformities. Standardized radiographs eliminate systematic errors associated with the obliquity of the patient's position and the relative distance of his feet with respect to the X-ray source and film. Various weight-bearing techniques have been reported in the literature. Gamble and Yale (1975) present a device developed by Hammond (1978) that produces comparable bi-planar radiographs of the spine, pelvis, knees, ankles and feet. The device consists of a platform where the patient is positioned in the static stance attitude. A vertical film cassette is located perpendicularly to the platform's surface and between the patient's feet for lateral foot views. Another film cassette is located underneath the platform for dorsoplantar and oblique views. The stance platform is adjustable to fore and aft positions as well as to rotation. Harris and Beath (1947) and Steel et al. (1980) have also utilized a standardized radiographic weight-bearing technique. For the antero-posterior radiographs, the subject was standing on the film cassette. The X-ray source was three meters above the film cassette; tilted $15^{\circ}$ from the vertical and pointed towards the patient's feet. For the second radiograph, the film cassette was vertically positioned so that it was in contact with the medial aspect of the foot. The X-ray source was positioned $1,2 \mathrm{~m}$ (48 in.) away and perpendicular to the cassette.

These techniques are well suited for ambulant patients. In this retrospective study, $34 \%$ of Friedreich ataxia patients were non-ambulant. A new technique had to be developed in order that standardized foot radiographs could be obtained from ambulant and nonambulant patients in the same "weightbearing" condition. Such a device shown in Fig. 1 has been recently built and is now routinely utilized in the clinic. Since the present retrospective study is based on data acquired prior to this recent development, the reader is referred to Sibille et al. (1981) for additional information pertaining to the mode of operation as well as to the application of this device.

To ensure some kind of standardization within the ambulant and nonambulant patient population, nonweight-bearing radiographs were taken as described in the following. For the antero-posterior radiograph, the patient was asked to sit on the radiographic table. Then, the plantar aspect of his feet were positioned directly on the film cassette in such a way that they were plantar flexed by $15^{\circ}$. This position is used to reduce the superimposition of the images of the talus and navicular on the radiograph. The $\mathrm{X}$-ray source was positioned $40 \mathrm{~cm}$ above the film cassette. For the lateral radiograph, the patient's legs were placed in the "frog position" with the medial aspect of the feet lying directly on the film cassette. The second radiograph was then taken. The authors are well aware that the results obtained from such a technique have to be interpreted with caution. A more precise and accurate technique such as described in Sibille et al. (1981) may provide additional information on

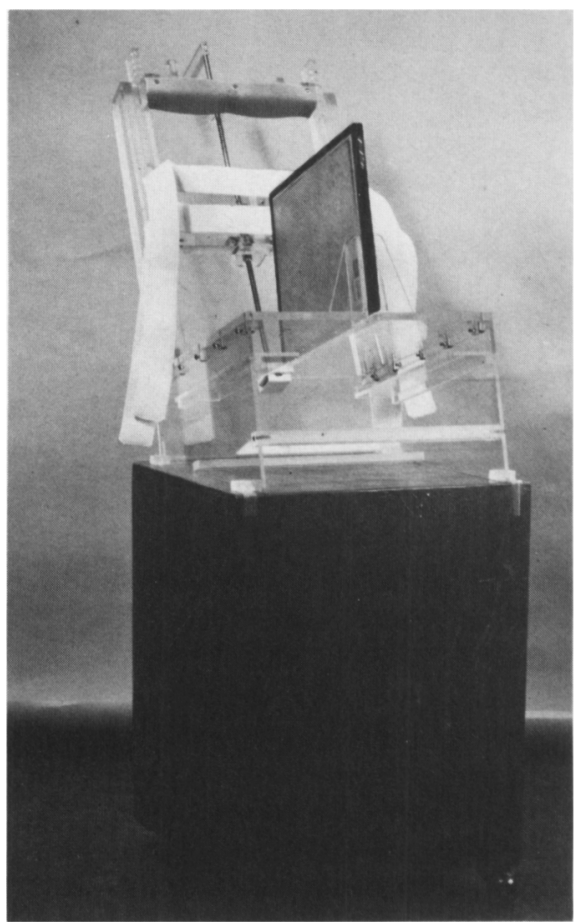

Figure 1 - Stool. 
the complex pathomechanics of the pes cavus deformity.

From each of the 132 pairs of radiographs, 56 points representing sixteen parameters taken from the anteroposterior film and twelve parameters taken from the lateral radiographs were digitized. The information was fed into a computer program which tabulated angle measurements.

\section{PRELIMINARY RESULTS}

Although twenty-eight parameters are included in the analysis, four of them are relevent to this study. They are, namely, the calcaneal inclination angle, first metatarsal inclination angle, inferior cortex of calcaneus-first metatarsal angle and the first-fifth metatarsals angle, schematically illustrated in Fig. 2. The results are classified arbitrarily in four age groups consisting each of a five year interval. The results obtained for this three year retrospective study on the pathomechanics of cavus foot deformity in Friedreich's ataxia are presented.

\section{Calcaneal Inclination Angle:}

The calcaneal inclination angle (CIA) is defined as the angle subtended by the horizontal plane and the cortical margin axis extended through the plantar calcaneal tuberosity and plantar aspect of the calcaneocuboid joint. The values measured for boys and girls are respectively illustrated in Fig. 3. For the boys, the calcaneal inclination angle remains fairly stable at a value of 29 degrees until the last age group. This value is within the range of a normal high arch. However, in the last age group, the inclination increases significantly by $28 \%$ to a value of 37 degrees. For the girls, the CIA values are somewhat similar to those reported for the boys. The major transition period seems to occur between the third and fourth age groups. The observed increases in the calcaneal inclination angle reflect a supination of the hindfoot or a cavus foot.

\section{First Metatarsal Inclination Angle:}

The first metatarsal inclination angle (FIA) is defined as the angle subtended by the horizontal plane and the central axis of the first metatarsal. The results for the first metatarsal inclination angle, illustrated in Fig. 4 seem to increase very rapidly from an average value of $29^{\circ}$ in the first age group, to $33^{\circ}$ in the third age group. These values are already higher than normal $\left(26^{\circ}\right)$. A sharper rise in the FIA index to $42^{\circ}$ is noticed between the third and fourth age groups. The latter value represents an increase of $13^{\circ}$ from the average value calculated for the first age group. These observations seem to indicate a subtalar varus and a forefoot valgus.

\section{Inferior Cortex of Calcaneus-First Metatarsal Angle:}

The inferior cortex of calcaneus-first metatarsal angle (CFA) is defined as an angle subtended by the cortical margin axis extended through the plantar calcaneal tuberosity and plantar aspect of the calcaneocuboid joint and by the central axis of the first metatarsal. For both boys and girls the apex of the inferior cortex of calcaneus-first metatarsal angle moves upwards. This can be closely associated, in part, to a cavus

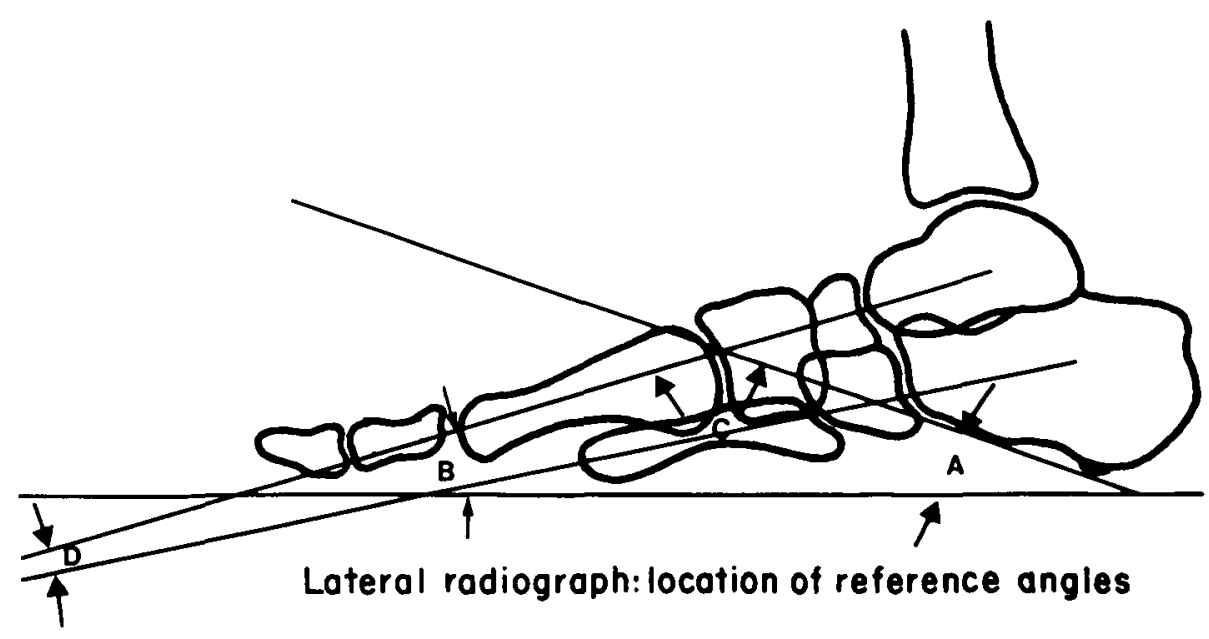

Figure 2 - Schematic illustration of the foot presenting four of the twenty-eight measured parameters.

A. Calcaneal inclination angle.

B. First metatarsal inclination angle.

C. Inferior cortex of calcaneus-first metatarsal angle and

D. First-fifth metatarsals angle.

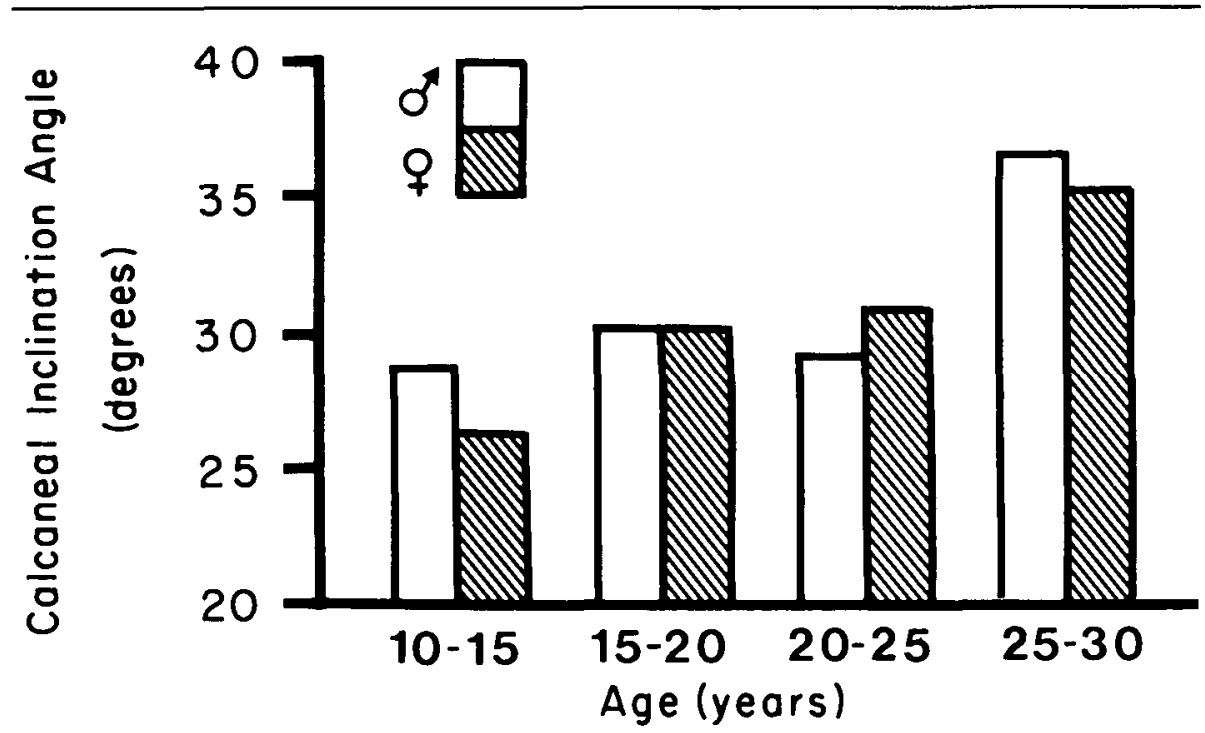

Figure $3-\mathrm{C}$ alcaneal inclination angle average values in boys and girls. 


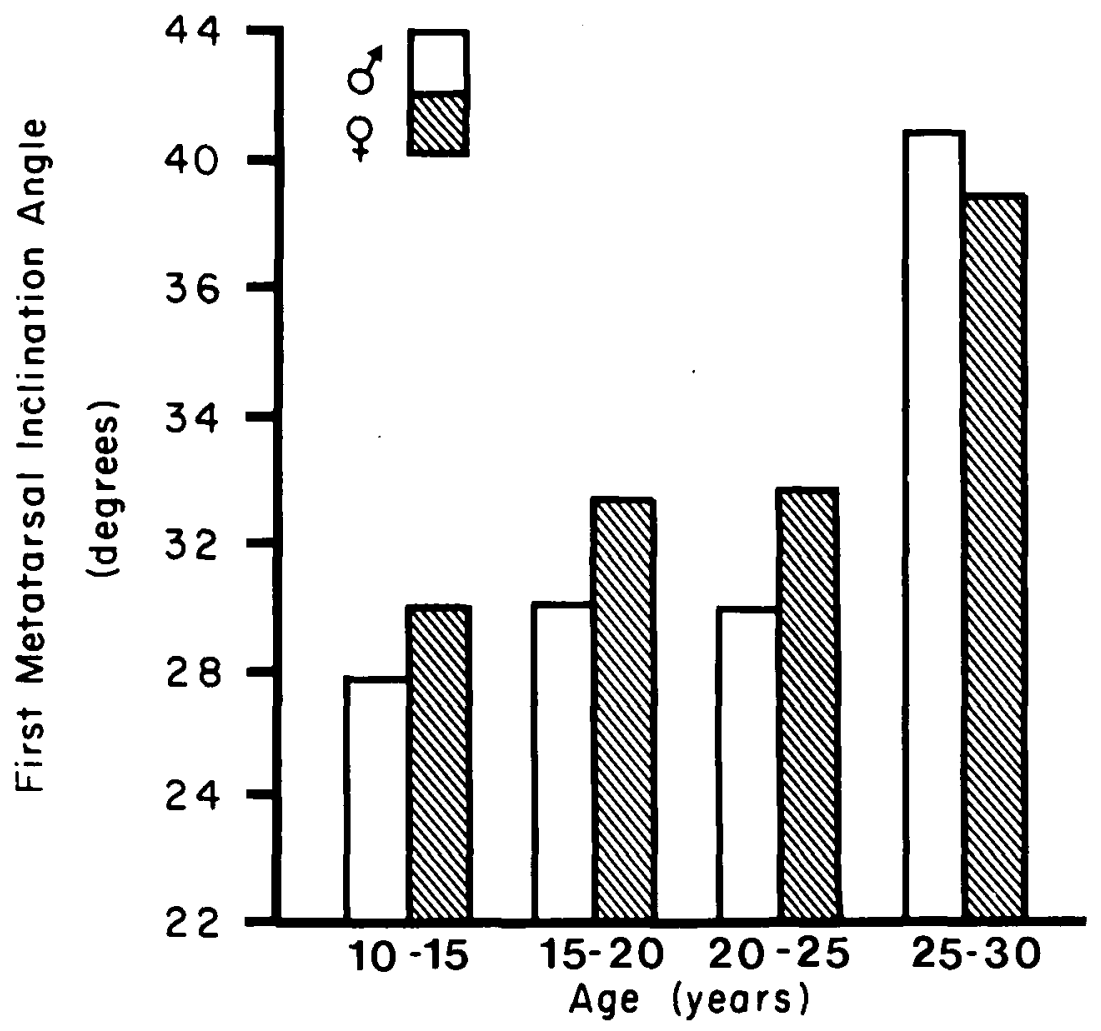

Figure 4 - First metatarsal inclination angle average values in boys and girls.

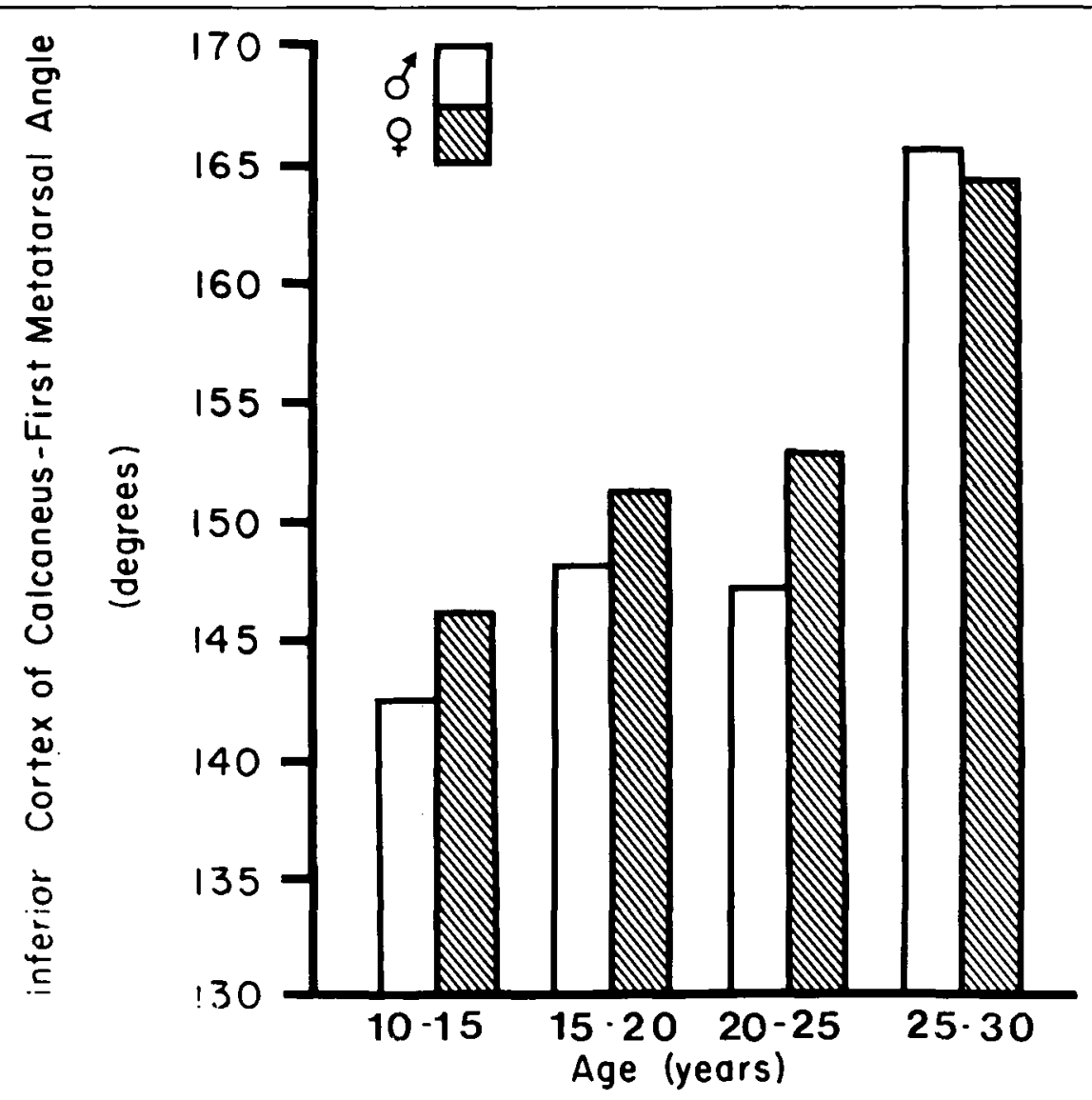

Figure 5 - Inferior cortex of calcaneus-first metatarsal angle average values in boys and girls. foot deformity. The values of the CFA index shown in Fig. 5, increase rapidly from about $142^{\circ}$ in the first age group to a value of $150^{\circ}$ in the third age group. These values are within the high normal range $\left(147^{\circ}\right)$. This increase may be the result of a more plantar flexed position of the first metatarsal as substantiated by an increase in the first metatarsal inclination angle values occurring during that same period of time. Between the third and fourth age groups, a sharp increase of $15^{\circ}$ in the values of the CFA index is observed. A marked increase in the values of the calcaneal inclination index, leading to a hindfoot supination, as well as monotonously increasing values of the FIA index are probably responsible for this latter observation in the CFA index values.

\section{First-Fifth Metatarsals Angle:}

The first-fifth metatarsals angle (FFA) is defined as the angle subtended by the central axis of the first metatarsal and by the central axis of the fifth metatarsal. The normal FFA values reported by Steel et al. (1980) is $10^{\circ}$. For both boys and girls the FFA index shown in Fig. 6 increased by $7^{\circ}$ and $3^{\circ}$ respectively, illustrating a relative pronation of the forefoot with respect to the hindfoot. For the last age group, the value of the FFA index is about $20^{\circ}$. A similar observation has been reported by Meary (1967). All of the FFA values for Friedreich's ataxia are much greater than that of normal $\left(14^{\circ}\right)$.

For all age groups studied, the individual parameters reported were generally in the high normal range or above. Stated otherwise, the feet usually present a mild cavus configuration. Our earliest records do not document the observation of a normal foot structure. This observation was also noticed by Meary (1967). Thus two situations can exist. Either the initial period of transformation of the normal foot into a mild cavus, occurs before the age of ten or the feet are already in a mild cavus condition from birth which then progresses into a severe cavus condition. To elucidate the above observations a more elaborated and detailed study has to be carried out. 


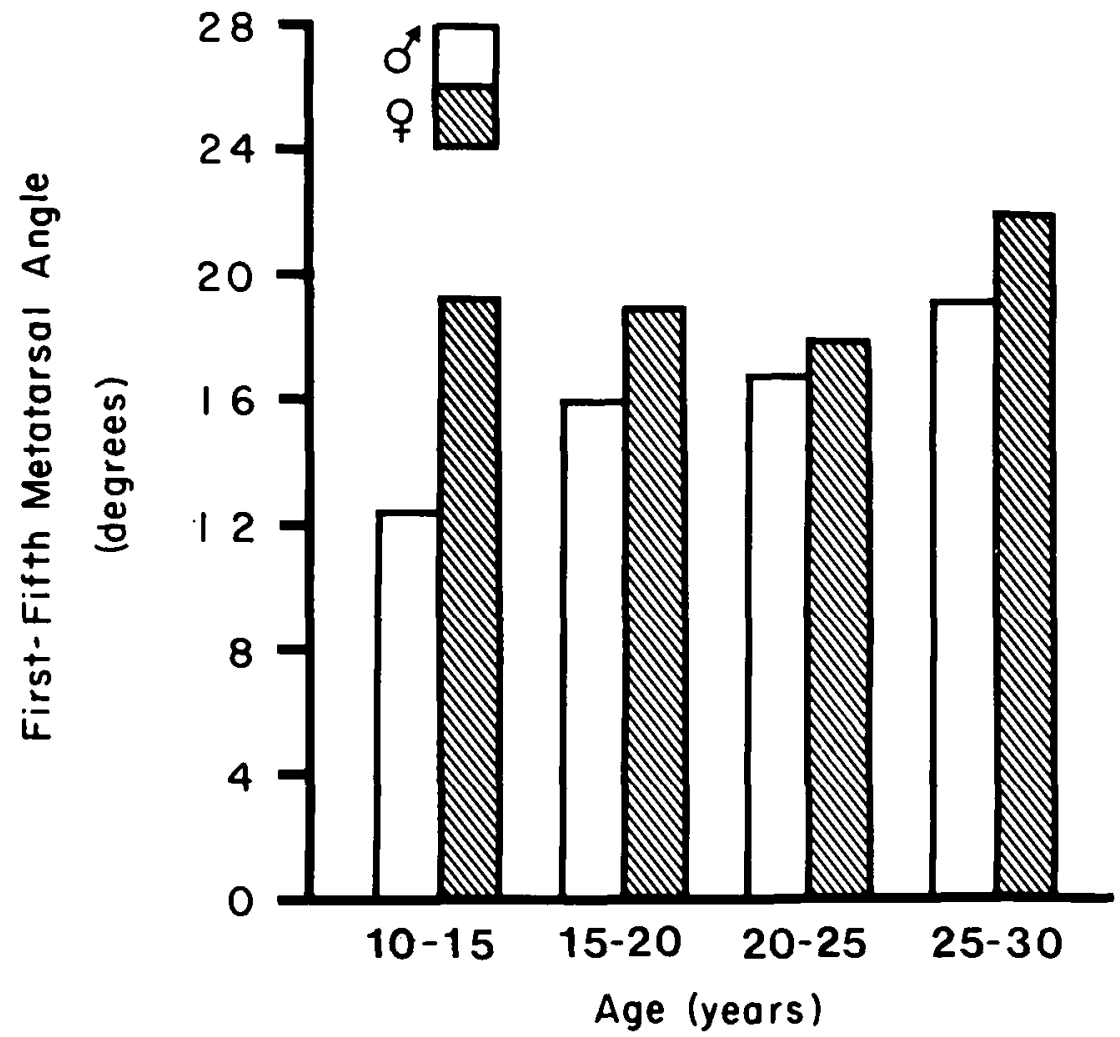

Figure 6 - First-fifth metatarsals angle average values in boys and girls.

\section{DISCUSSION}

From the above results a preliminary quantitative description of the pes cavus evolution in Friedreich ataxia patients was attempted. Three stages may be identified to describe the evolution of cavus foot in this type of neurological disorder. In the first stage, only the first metatarsal is involved. It goes into a gradual but progressive plantar flexed position. This phenomena is observed at the very onset. In the second stage a pronation of the metatarsals is occurring as illustrated by a slight increase in the first-fifth metatarsals angle observed in the second age group. Both the pronated first ray and the forefoot pronation produce a projected image on the lateral radiograph which can be associated to a cavus foot deformity. This results in a sharp rise in CFA index values during the third age group. Since the deformity is mainly located in the forefoot, the cavus may still be reducible. Finally, in the third stage the calcaneus is involved. During the third age group, the calcaneus may be compensating for the forefoot pronation which shows, at that time, an increase of $13 \%$ in the values of the FFA index. With the calcaneus going into supination, the lateral radiograph of the foot shows a more advanced cavus deformity as evidenced by the values of the CFA index. The cavus may then become less reducible.

It is hoped that the results obtained from this study as well as the above description explaining the interaction between the osseous components in pes cavus provide a better understanding of this complex deformity. Furthermore, these results will serve as guidelines to our on-going research in cavus foot deformity where a new radiographic device is utilized to obtain stereoradiographs enabling a three dimensional geometric reconstruction of the foot by means of a mathematical model.

\section{ACKNOWLEDGEMENTS}

Financial support from l'Association Canadienne de l'Ataxie de Friedreich is greatly appreciated.

\section{REFERENCES}

BARBEAU, A. et al. (1976) Friedreich's Ataxia, Quebec Cooperative Study. Phase One. Can. J. Neurol. Sci., 3:269-397.

BARBEAU, A. et al. (1978) Friedreich's Ataxia, Quebec Cooperative Study. Phase Two, Part One. Can. J. Neurol. Sci., 5:5 7-165.

BARBEAU, A. et al. (1979). Friedreich's Ataxia, Quebec Cooperative Study. Phase Two, Part Two. Can. J. Neurol. Sci., 6:145-319.

BENTZON, P.G.K. (1933). Pes Cavus and M. Peroneus Longus. Acta Orthop. Scandinavica, $4: 50$.

BREWERTON, P.A., SANDIFER, P.H. and SWEETNAM, D.R. (1963). Idiopathic Pes Cavus. An Investigation into its Etiology. Brit. Med. J., 2:659-661.

GAMBLE, F.O. and YALE, I. (1975). Clinical Foot Roentgenology. Robert E. Krieger Publishing Co. Inc., 434 pages.

GARCEAU, G.J. and BRAHMS, M.A. (1956). A Preliminary Study of Selective PlantarMuscle Denervation for Pes Cavus. J. Bone and Joint Surg., 38-A:553-562.

HAMMONDS, C.M. (1970). Hammonds' Posture-Poser, U.S. Pat., 3525557.

HARRIS, R.I. and BEATH, T. (1952). Army Foot Survey. Vol. 1 and 2, 2nd Ed. Ottawa, National Research Council of Canada.

HICKS, J.H. (1952). The Mechanics of the Foot I - The Joints. J. Anat., 87:345-357.

INMAN, V.T. (1976). The Joints of the Ankle. The William and Wilkins Company, Baltimore, 177 pages.

MEARY, R. (1967). Le pied creux essentiel. Revue de chirurgie orthopédique et réparatrice de l'appareil moteur, 53:390-410.

NAPIER, J.R. (1957). The Foot and the Shoe. Physiotherapy, 43:65-74.

PAUlOS, L., COLEMAN, S.C. and SAMUELSON, K.M. (1980). Pes Cavovarus. J.B.J.S., $62: 942-953$.

SIBILLE, J., TREMBLAY, G.R., THIRY, P.S. and ALLARD, P. (1981). Reference Apparatus for Normalized Bi-Planar Radiographs of the Foot. Fifth Annual Conference of the American Society of Biomechanics, Cleveland, Ohio, U.S.A.

STEEL, M.W. III, JOHNSON, K.A., DEWITZ, M.A. and ILSTRUP, D.M. (1980). Radiographic Measurements of the Normal Adult Foot. Foot and Ankle, 1:151158.

TUREK, S.L. (1977). Orthopaedics: Principles and their Application. J.B. Lippincott Company, 1474 pages.

TYRER, J.H. (1975). Familial Pes Cavus. Handbook of Clinical Neurology, 21:263269. 